\title{
EFEKTIVITAS APLIKASI PHET DISERTAI LKS MATERI GERAK DAN GAYA UNTUK PEMBELAJARAN IPA DI SMP
}

Inggrid Ayu Amala ${ }^{1}$, Indrawati ${ }^{2}$, Iwan Wicaksono ${ }^{3}$

1,3Program Studi S1 Pendidikan IPA, Universitas Jember, Indonesia

${ }^{2}$ Program Studi Magister Pendidikan IPA, Universitas Jember, Indonesia

Corresponding author email: inggridayu8@gmail.com

\section{Info Artikel}

Diterima:

15 Juli 2020

Disetujui:

03 Desember 2020

Dipublikasikan:

15 Desember 2020

\begin{abstract}
Abstrak:
Penelitian ini bertujuan untuk menggambarkan efektivitas aplikasi PhET yang dilengkapi dengan lembar kerja tentang gerak dan kekuatan untuk pembelajaran sains di sekolah menengah pertama. Jenis penelitian ini adalah deskriptif yang dilakukan pada siswa SMP kelas 8 di salah satu SMP di Kabupaten Lumajang. Efektivitas pembelajaran ditunjukkan dari kegiatan belajar dan meningkatkan prestasi belajar siswa. Data dikumpulkan dengan teknik observasi dan tes. Data aktivitas pembelajaran dianalisis secara deskriptif menggunakan persentase dan peningkatan prestasi siswa dianalisis dengan gain dinormalisasi $(\mathrm{Ng})$. Satu kelompok pre-test dan desain pascarencana digunakan dalam proses pengumpulan data. Hasil penelitian menunjukkan bahwa rata-rata aktivitas belajar siswa untuk empat indikator aktivitas (visual, mental, motorik, dan emosional) adalah 79,94\% termasuk dalam kategori baik dan rata-rata peningkatan hasil belajar adalah 0,67 (kategori sedang). Kesimpulan dari penelitian ini adalah pembelajaran IPA di SMP dengan menggunakan aplikasi PhET cukup efektif dalam meningkatkan hasil belajar siswa dan rata-rata aktivitas belajar siswa menjadi baik.
\end{abstract}

Kata kunci: Efektivitas, PhET, lembar kerja, prestasi, belajar

\begin{abstract}
:
This study aims to describe the effectiveness of the PhET application which is equipped with worksheets about motion and force for science learning in junior high schools. This type of research is descriptive which is conducted on 8th grade junior high school students in one of junior high school in Lumajang Regency. The effectiveness of learning is shown from learning activities and increasing students'achievement. Data were collected by observation and test techniques. Learning activity data were analyzed descriptively using percentages and increasing students' achievement were analyzed with normalized gain $(\mathrm{Ng})$. One group pre-test and post-plan design are used in the data collection process. The results showed that the average student learning activity for four activity indicators (visual, mental, motor, and emotional) was 79,94\% included in the good category and the average increase in learning outcomes was 0.67 (medium category). The conclusion of this study is the learning of science of motion and force in junior high school by using the PhET application is quite effective in improving student learning outcomes and the average student learning activity become good.
\end{abstract}

Keywords: Effectiveness, PhET, worksheets, achievement, learning 


\section{Pendahuluan}

Ilmu Pengetahuan Alam (IPA) merupakan terjemahan dari kata natural sciences yaitu ilmu yang mempelajari tentang alam dan gejalanya yang terdiri atas proses, produk, dan sikap (Carin dan Sund, 1975; Abrucasto, 1982; Sutarto dan Indrawati, 2013;) dan pada era teknologimenjadi empat unsur yaitu proses, produk, sikap, dan teknologi (Nau dan Missa, 2018) atau aplikasinya (Mariana dan Praginda, 2009). IPA merupakan salah satu mata pelajaran yang harus diberikan pada siswa pada jenjang SMP. Pembelajaran IPA yang efektif seyogyanya harus selalu dipikirkan oleh para guru IPA. Pembelajaran IPA yang efektif tentunya harus sesuai dengan hakikat IPA. Oleh karena itu, guru IPA harus memiliki pengetahuan dan keterampilan untuk menentukan strategi agar pembelajarannya efektif.

Pembelajaran IPA yang baik adalah pembelajaran yang sesuai dengan hakikat IPA dan hakikat pembelajarannya. Selain sesuai dengan hakikatnya, dalam pembelajaran harus memperhatikan karakter materi IPA dan karakter siswa sebagai pebelajar (Sutarto dan Indrawati, 2013). Karakter materi IPA antara lain adalah konkret atau abstrak, sederhana atau kompleks, konsep lama atau baru bagi siswa, bersifat fisik, sosial, atau logikomatematik (Indrawati dan Sutarto, 2013). Materi IPA yang bersifat abstrak dan bersifat logiko-matematik biasanya yang menyebabkan IPA sering dikatakan oleh siswa sebagai mata pelajaran yang sulit.Secara umum, karakter materi tersebut tetap hanya bagaimana siswa memahami bisa berbeda-beda tergantung tingkat perkembangan intelektual dan pengalaman siswa.

Karakter siswa setiap individu tidak bisa diseragamkan, setiap individu berbeda karena pengalamnnya. Karakter siswa antara lain dapat ditandai dengan gaya belajarnya. Dunn dan Dunn (1992), mendefinisikan gaya belajar sebagai cara setiap siswa mulai berkonsentrasi, memproses dan mengingat informasi baru dan sulit. Bransford, et al (1999) menyatakan bahwa mengetahui bagaimana siswa belajar dapat membantu guru dalam menentukan strategi pembelajaran. Dengan demikian, untuk menghasilkan pembelajaran IPA yang efektif maka guru perlu memahami karakteristik siswanya.

Karakter siswa SMP di era digital atau era Tektologi Informasi dan Teknologi (TIK) tentu berbeda dengan siswa-siswa di era sebelumnya. Hasil observasi di sebagian besar SMP di Kabupaten Lumajang menunjukkan bahwa hampir semua siswanya terampil menggunakan fasilitas TIK, seperti handphone dan komputer. Hampir semua menu dan fitur yang ada dalam sarana tersebut mereka dapat mengoperasikan. Hasil wawancara dengan beberapa siswa SMP, sebagian besar mereka terampil menggunakan sarana tersebut karena membaca dan belajar dari orang-orang di sekitarnya yang memiliki pengalaman tersebut. Dengan kondisi tersebut maka merancang pembelajaran IPA di SMP dengan bantuan media TIK memungkinkan dapat dilakukan dan dapat memudahkan siswa untuk menerima informasi yang dipesankan. Hal ini dikuatkan oleh Wicaksono et al (2017) yang menyatakan bahwa TIK sebagai media memberikan kontribusi besar dalam pembelajaran yang menarik dan dapat menjadi salah satu kunci untuk menumbuhkan penguasaan konsep siswa.Salah satu media berbasis TIK adalah aplikasi PhET(Physics Education Technology).

Aplikasi PhET merupakan salah satu bentuk eksperimen semu (virtual experiment) melalui laboratorium semu (virtual laboratory) yang dikembangkan oleh Universitas Colorado di Boulder tahun 2012 (Perkins et al, 2012) PhET merupakan simulasi interaktif fenomena-fenomena fisis berbasis riset yang menggabungkan hasil penelitian sebelumnya yang memungkinkan para siswa dapat menghubungkan fenomena kehidupan nyata dan ilmu yang mendasarinya, yang pada akhirnya dapat memperdalam pemahaman dan meningkatkan minat mereka terhadap ilmu fisika. Simulasi PhET tidak hanya digunakan dalam fisika, tetapi juga pada sains lainnya seperti kimia, biologi, dan geologi. Simulasi PhET bersifat interaktif yang dapat mengajak siswa untuk belajar dengan cara mengeksplorasi secara langsung. Selain itu, aplikasi PhET dapat juga membuat materi fisika yang sangat kecil (mikroskopis) atau tidak dapat dilihat dengan mata telanjang seperti atom, elektron, medan listrik, foton, jalannya sinar dapat diperlihatkan. Aplikasi PhET juga menyediakan fasilitas untuk mengeksplorasi secara kuantitatif dengan menggunakan alat-alat ukur layaknya di lab riil, seperti stop-watch, termometer, jangka sorong, mistar, neraca, dan lain-lain. Dengan fasilitas yang diberikan PhET maka hakikat IPA sebagai proses dapat diimplementasikan walaupun tidak melalui lab riil, tetapi melalui lab virtual.

Penggunaan aplikasi PhET untuk pembelajaran tidak cukup siswa hanya mengamati jalannya simulasi $P h E T$, tetapi perlu prosedur dalam mengoperasikan dan menuangkan hasil pengamatannya dalam lembar kerja yang biasa disebut lembar kerja siswa (LKS). Dengan LKS, guru dapat memandu aktivitas siswa selama pembelajatran dengan menggunakan aplikasi PhET. Selain itu, guru dapat memperoleh informasi apa saja yang bisa ditangkap oleh siswa dari aplikasi PhET tersebut, sehingga Efektivitas Aplikasi Phet.... (Inggrid Ayu Amala, dkk) hal:85-91 
dapat digunakan untuk mengukur ketercapaian tujuan pembelajaran. Selama belajar dengan aplikasi $P h E T$, siswa dapat menggunakan beberapa aktivitas belajarnya.Sekurang-kurangnya ada empat aktivitas belajar dari delapan aktivitas belajar menurut Nasution (1995). Empat aktivitas tersebut adalah mental (misalnya menganalisis hubungan antarkonsep), visual (misalnya mengamati gambar dan langkahlangkah percobaan), motorik (melakukan percobaan secara virtual), dan emosional (misalnya senang dan berminat untuk belajar). Empat aktivitas tersebut dimungkinkan dapat diwujudkan ketika siswa belajar dengan aplikasi PhET.

Gerak dan gaya adalah materi yang diberikan pada siswa kelas 8 SMP (Kemendikbud, 2017). Istilah gerak mungkin sudah akrab dalam kehidupan sehari-hari siswa, tetapi hubungan antara konsep gerak dan gaya tentu tidak sederhana bisa dipahami dengan mudah bagi siswa SMP. Kesulitan tersebut dapat ditunjukkan dari beberapa hasil penelitian yang menjelaskan bahwa masih dijumpai anak-anak SMP yang miskonsepsi terhadap konsep gerakdangaya (Istiadah, et al, 2016; Wiyono et al, 2016). Hal ini menunjukkan bahwa konsep-konsep yang bersifat sederhana seperti konsep gerak dan gaya belum tentu dipahami dengan mudah dan benar oleh siswa. Oleh karena itu, alternatif pembelajaran konsep gerak dan gaya di SMP perlu dipikirkan dengan baik agar tidak terjadi kesalahan konsep dan pembelajaran efektif.

Sebelumnya telah dijelaskan bahwa pembelajaran IPA yang baik adalah sesuai dengan hakikatnya sehingga pembelajaran efektif, artinya siswa aktif dan tujuan pembelajaran yang ditargetkan tercapai. Hal ini sesuai dengan pendapat Nieveen (1999) bahwa pembelajaran dapat dikatakan berhasil atau efektif jika siswa aktif selama proses pembelajaran dan hasil belajarnya meningkat. Hasil penelitian (Nurhayati et al, 2014) menunjukkan bahwa pembelejaran dengan demonstrasi media software PhET efektif dalam meningkatkan hasil belajar siswa pada materi listrik dinamis. Penelitian lainyang dilakukan oleh Maulidah dan Prima (2018) menyimpulkan bahwa PhET sebagai laboratorium virtual dalam mempelajari gelombang dan suara menunjukkan hasil yang baik pada aspek kognitif dan lingkungan laboratorium IPA. Penelitian Prihatiningtyas, et al (2013) menyimpulkan bahwa hasil belajar dengan menggunakan simulasi PhET lebih efektif dibandingkan dengan kit sederhana dalam membantu siswa untuk memahami konsep. Kemudian hasil penelitian Utami dan Arif (2016) menunjukkan bahwa penggunaan LKS dalam pembelajaran dengan aplikasi PhET membuat pembelajaran menjadi efektif. Informasi-informasi tersebut menunjukkan bahwa aplikasi PhET dilengkapi LKS efektif untuk pembelajaran beberapa konsep IPA.

Berdasarkan uraian di atas maka muncul masalah bagaimana efektivitas pembelajaran pada aktivitas belajar dan peningkatan hasil belajar siswa jika aplikasi PhET yang dilengkapi LKS pada materi gerak dan gaya untuk pembelajaran IPA di SMP? Penelitian ini bertujuan untuk mendeskripsikan efektivitas pembelajaran IPA di SMP untuk materi gerak dan gaya dengan menggunakan aplikasi PhET yang dilengkapi LKS dalam meningkatkan hasil belajar dan aktivitas belajar siswa.

\section{Metode}

Penelitian ini merupakan jenis penelitian deskriptif kuantitatif. Subyek penelitian adalah siswa kelas 8 sebanyak 31 anak yang sedang belajar materi gerak dan gaya di salah satu SMP di Kabupaten Lumajang, Jawa Timur. Untuk menjawab rumusan masalah maka penelitian meminjam/menggunakan rancangan penelitian one group pre-tes post-tes yang biasa dikenal sebagai rancangan penelitian pre-eksperimen. Dalam penelitian ini efektivitas pembelajaran ditunjukkan dari peningkatan hasil belajar dari sebelum pembelajaran (pre-tes) ke setelah pembelajan (post-tes) dan aktivitas belajar siswa selama pembelajaran berlangsung. Teknik yang digunakan untuk pengumpulan data peningkatan hasil belajar adalah tes. Tes yang digunakan untuk materi gerak adalah 10 butir tes soal obyektif dan 5 butir soal esai. Untuk materi gaya ada 17 butir soal berbentuk esai. Dalam penelitian ini tes yang digunakan untuk pre-test sama dengan yang digunakan untuk post-test. Peningkatan hasil belajar dianalisis dengan menggunakan normalized gain $(\mathrm{Ng})$, yang dirumuskan oleh Meltzer (2002) seperti berikut:

$$
N g=\frac{\text { Skor post }- \text { skor pre }}{\text { Skor maks }- \text { skor pre }}
$$


$\mathrm{Ng}$ adalah peningkatan hasil belajar, skor post adalah skor setelah pembelajaran, skor pre adalah skor sebelum pembelajaran, dan skor maksimum adalah skor tertinggi dari kelompok skor pre dan skor post-tes. Kriteria peningkatan hasil belajar menurut Savinainen dan Scott (2002) dapat ditunjukkan pada Tabel 1.

Tabel 1. Kriteria $\mathrm{Ng}$

\begin{tabular}{cc}
\hline$N g$ & Kriteria \\
\hline$N g>0,7$ & Tinggi \\
$0,3 \leq N g \leq 0,7$ & Sedang \\
$N g<0,3$ & Rendah \\
\hline
\end{tabular}

Teknik yang digunakan untuk mengumpulkan data aktivitas belajar adalah observasi. Teknik yang digunakan untuk menganalisis aktivitas belajar adalah deskriptif kuantitatif dengan menggunakan teknik analisis persentase, yang dirumuskan oleh Widodo dan Lusi (2013) seperti berikut.

$$
N k=\frac{R}{S M} x 100 \%
$$

$N k$ adalah nilai persen aktivitas belajar yang diharapkan, $R$ adalah skor aktivitas belajar yang diperoleh siswa, dan SM adalah skor maksimal aktivitas belajar siswa. Kriteria aktivitas belajar siswa menurut Widodo dan Lusi (2013) ditunjukkan pada Tabel 2.

Tabel 2. Kriteria aktivitas belajar siswa

\begin{tabular}{ll}
\hline Kisaran skor & Kriteria \\
\hline $86 \%-100 \%$ & Sangat Baik \\
$76 \%-85 \%$ & Baik \\
$60 \%-75 \%$ & Cukup \\
$55 \%-59 \%$ & Kurang \\
$\leq 54 \%$ & Sangat Kurang \\
\hline
\end{tabular}

\section{Hasil Penelitian dan Pembahasan}

\section{a. Peningkatan Hasil Belajar Siswa}

Peningkatan hasil belajar $(\mathrm{Ng})$ pada materi gerak dan pada materi gaya dengan menggunakan aplikasi PhET disertai LKS dapat ditunjukkan dengan grafik Gambar 1.

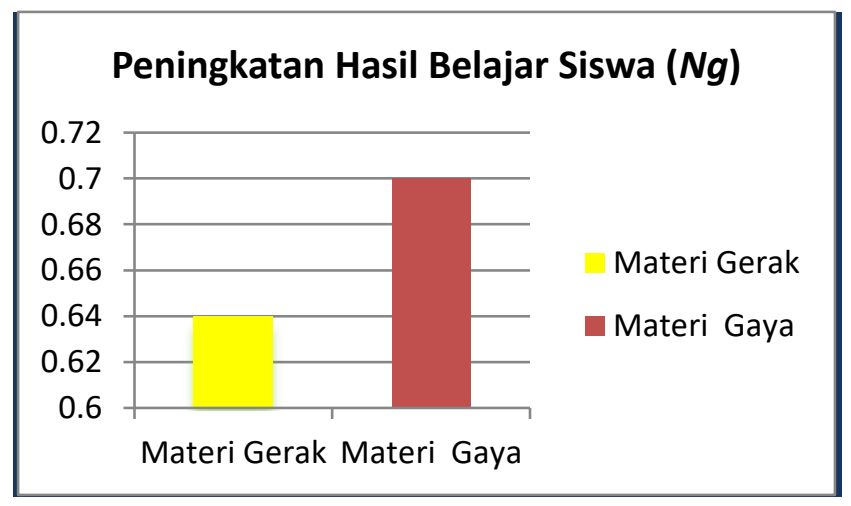

Gambar 1. Grafik $N g$ hasil belajar siswa pada materi gerak dan materi gaya

Gambar 1 menunjukkan bawa rerata peningktan hasil belajar siswa pada materi gerak dan gaya tersebut berbeda. Rerata peningkatan hasil belajar siswa dengan pembelajaran menggunakan 
aplikasi PhET disertai LKS untuk materi gerak adalah 0,64 dan untuk materi gaya adalah 0,7. Walaupun $\mathrm{Ng}$ pada materi gaya lebih besar dari $\mathrm{Ng}$ pada materi gerak, namun keduanya masih berada pada kategori sedang atau rerata $\mathrm{Ng}$ adalah 0,64 (sedang).

\section{b. Aktivitas belajar siswa}

Data aktivitas belajar untuk empat indikator selama proses pembelajaran dengan aplikasi PhET disertai LKS untuk pembelajaran gerak dan gaya dapat ditunjukkan pada Gambar 2.

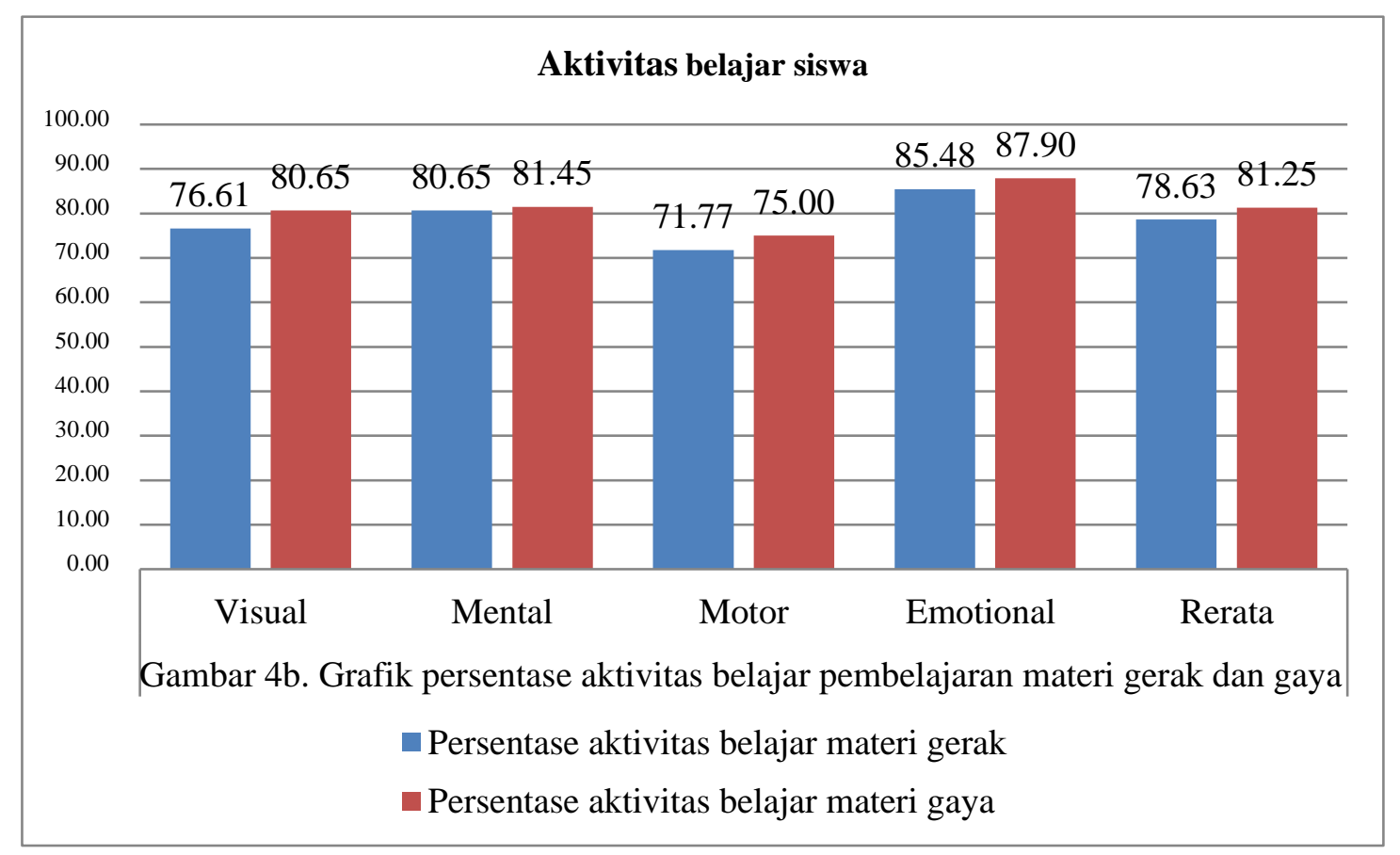

Gambar 2. Grafik rerata aktivitas belajar siswa pada materi gerak dan gaya

Gambar 2 menunjukkan rerata nilai setiap indikator aktivitas belajar siswa pada pembelajaran materi gerak dan pembelajaran materi gaya. Aktivitas belajar siswa dinilai oleh 2 observer setiap 5 menit sekali untuk mengetahui pemunculan setiap indikatornya. Pada saat pembelajaran materi gerak, persentase rerata aktivitas belajar visual, mental, motor, dan emosional berturut-turut adalah 76,61\% (baik); 80,65\% (baik); 71,77\% (baik); dan 78,63\% (sangat baik). Pada saat pembelajaran materi gaya, menunjukkan rerata persentase aktivitas belajar siswa berturut-turut adalah 80,65\% (baik); 81,45\% (baik); $75,00 \%$ (baik); dan 87,90\% (sangat baik). Rerata aktivitas belajar siswa pada pembelajaran materi gerak adalah $78,63 \%$ dan $81,25 \%$ untuk materi gaya, yang keduanya berkategori baik.

Secara rata-rata aktivitas belajar pada pembelajaran materi gerak dan gaya relatif sama, tetapi ada hal yang menarik bahwa rerata persentase aktivitas belajar siswa terendah adalah pada aktivitas motorik dan tertinggi pada aktivitas emosional. Hal ini menggambarkan bahwa pembelajaran dengan aplikasi PhET disertai LKS untuk materi gerak dan gaya belum mampu membuat siswa memiliki aktivitas motorik sangat baik. Hal ini antara lain karena menggunakan laboratorium virtual, sehingga siswa tidak secara langsung menggunakan aktivitas fisik dalam melakukan percobaan (hand-on activity), tetapi menggunakan aktivitas otak (mind-on activity).

Hasil yang menggembirakan adalah rerata aktivitas emosional siswa termasuk pada kategori sangat baik. Hal ini menunjukkan bahwa siswa sangat senang dan bersemangat belajar atau motivasi belajar tinggi dengan menggunakan aplikasi PhET. Hal ini sesuai dengan hasil penelitian (Prima, et al, 2018) bahwa pembelajaran dengan aplikasi PhET berpengaruh terhadap motivasi belajar. Faktor emosional ini penting karena ada pengaruh motivasi belajar terhadap hasil belajar siswa (Fitriwati, 2012). 


\section{Simpulan}

Berdasarkan hasil penelitian dan pembahasannya maka dapat disimpulkan bahwa pembelajaran IPA di SMP dengan menggunakan aplikasi PhET disertai LKS pada materi gerak dan gaya efektif untuk meningkatkan hasil belajar pada kategori sedang dan rerata aktivitas belajar pada kategori baik.

\section{Referensi}

Abruscato, J. 1982. Teaching Children Science. New Jersey: PrenticeHall, Inc., Englewood Cliffs.

Bransford, J. D., A. L. Brown, dan R. R. Cocking (Eds.). 1999. How people learn: Brain, mind, experience, and school. National Academy Press.

Carin, A. A., dan R. B. Sund 1975. Teaching Modern Science, Second Edition. Ohio: Charles E. Merrill Publishing Company A Bell \& Howell Company.

Dunn, R., dan K. Dunn. 1992. Teaching secondary students through their individual learning styles: Practical approaches for grades 7-12. Boston: Allyn and Bacon.

Fitriwati, D.G. 2018. The effect of motivation on the learning achievement. IJIELT. 4(1): 198-207.

Istiadah, L. L. Yuliati, dan S. Zubaidah. 2016. Penguasaan Konsep Gerak pada Siswa SMP.Prosiding Semnas Pendidikan IPA Pascasarjana UM. 1: 1006-1013.

Kemendikbud. 2017. Model silabus Mata Pelajaran IPA SMP/M.Ts. Kepmendikbud: Jakarta.

Maulidah, S, S., dan E,C, Prima. 2018. Using Physics Education Technology as Virtual Laboratory in Learning Waves and Sounds. Journal Of Science Learning. 1(3): 116-121.

Mariana, A., dan W.Praginda. 2009. Hakikat IPA dan Pendidikan IPA untuk guru SD. Jakarta: Pusat Pengembangan dan Pemberdayaan Pendidik dan Tenaga Kependidikan IPA (PPPPTK IPA).

Meltzer., dan E. David. 2002. The Relationship Between Mathematics Preparation And Conceptual Learning Gain In Physics: A Possible Hidden Variable In Diagnostic Pretest Scores. American Journal Physics. 70(2): 1259-1267.

Nasution. 1995. Dikdaktik Asas-asas Mengajar. Jakarta: Bumi Aksara.

Nau, G,W., dan M. Missa. 2018. Pelatihan Praktikum Sederhana Bagi Guru-Guru IPA SMP Kecamatan Mollo Utara Kabupaten Timor Tengah Selatan.Jurnal Pengambdian Kepada Masyarakat. 24 (4).

Nieveen, N. 1999. Prototyping to Reach Product Quality. Dalam Plomp, T; Nieveen, N; Gustafson, K; Branch, R.M; dan van den Akker, J (eds). Design Approaches and Tools in Education and Training. London: Kluwer Academic Publisher.

Nurhayati., S, Fadilah, dan Mutmainnah . 2014. Penerapan Metode Demonstrasi Berbantuan Media Animasi Software PhET terhadap Hasil Belajar Siswa dalam Materi Listrik Dinamis Kelas X Madrasah Aliyah Negeri 1 Pontianak. Jurnal Pendidikan Fisika dan Aplikasinya. 4 (2):1-7.

Perkins, K., E. Moore, N. Podolefsky, K. Lancaster, dan C. Denison. 2012. Towards research-based strategies for using PhET simulations In Middle School Physical Science Classes.AIP Conference Proceedings, 1413, 295-298.

Prihatiningtyas, S., T. Prastowo, dan B. Jatmiko. 2013. Implementasi Simulasi PhET dan Kit Sederhana untuk Mengajarkan Keterampilan Psikomotor Siswa pada Pokok Bahasan Alat Optik.Jurnal Pendidikan IPA Indonesia. 2(1).

Prima, E. C., A. R. Putri, dan R. Nuryani. 2018. Learning Solar System using PhET Simulation to Improve Students' Understanding and Motivation. Journal of Science Learning.1(2).60-70.

Savinainen, A., dan P. Scott. 2002. The Force Concept Inventory: A Tool For Monitoring Student Learning. Physics Education. 37(1): 45-52.

Sutarto dan Indrawati. (2013). Strategi Belajar Mengajar Sains. UPT Penerbitan UNEJ. Jember. 
Utami, I,T., dan A. Arief, 2016. Pengembangan Lembar Kerja Siswa (LKS) Dengan Laboratorium Virtual PhET Pada Pokok Bahasan Teori Kinetik Gas Kelas XI SMA Negeri 2 Sumenep. Jurnal Inovasi Pendidikan Fisika. 5(2): 99-105.

Wicaksono, I., Wasis, dan Madlazim. 2017. The Effectiveness Of Virtual Science Teaching Model (VSTM) To Improve Student's Scientific Creativity And Concept Mastery On Senior High School Physics Subject. Journal Of Baltic Science Education. 16 (4).

Widodo., dan L. Widayanti. 2013. Peningkatan Aktivitas Siswa Belajar Dan Hasil Belajar Siswa Dengan Metode Problem Based Learning Pada Siswa Kelas VII MTS Negeri Donomulyo Kulon Progo Tahun Pelajaran 2012/2013. Jurnal Fisika Indonesia.49(XVII).

Wiyono, F. M., Sugiyanto, dan E. Yulianti. 2016. Identifikasi hasil analisis miskonsepsi gerak menggunakan instrumen diagnostik three TIER pada Siswa SMP. Jurnal Penelitian Fisika dan Aplikasinya (JPFA). 6(2): 61-69. 